\title{
Patterns of spatio-temporal distribution as criteria for the separation of planktic foraminiferal species across the Danian-Selandian transition in Spain
}

Ignacio Arenillas

Acta Palaeontologica Polonica 57 (2), 2012: 401-422 doi: http://dx.doi.org/10.4202/app.2010.0076

Danian-Selandian (D-S) planktic foraminiferal taxonomy and paleoecology, including the most problematic index-species of biochronological schemes, are here revised based on qualitative and quantitative data from the Caravaca and Zumaia sections, Spain. As a first step the morphological and microtextural diagnostic characters are revised in order to achieve appropriate morphological distinctions of the investigated species. The analysis of latitudinal preferences of the planktic foraminiferal species deduced from a comparison of their relative abundances at Caravaca (western Tethyan subtropical waters) and Zumaia (central North Atlantic warm temperate waters) in suite with a statistical comparison of quantitative stratigraphic distributions of the species at Caravaca have shown several divergences in their patterns of spatio-temporal distribution (i.e., in their latitudinal preferences and quantitative stratigraphic distributions). This analysis allowed taxonomical separation of 41 species from the following genera: Eoglobigerina, Subbotina, Parasubbotina, Globanomalina, Luterbacheria, Acarinina, Igorina, Morozovella, Praemurica, Chiloguembelina, and Zeauvigerina. Morphologically convergent species pairs such as Acarinina trinidadensis and Praemurica inconstans, Acarinina praecursoria and Acarinina uncinata, Morozovella conicontruncata and Morozovella angulata, or Morozovella cf. albeari and Igorina albeari, are well differentiated using aforementioned criteria. Since some of the species are index-taxa, the taxonomic refinements are essential to clarify and compare the planktic foraminiferal zonations from the Danian-Sealandian transition. A new lower/higher $(\mathrm{L} / \mathrm{H})$ latitude taxa ratio is proposed for paleoclimatic interpretations based on the paleoecological and quantitative studies. Fluctuations in $\mathrm{L} / \mathrm{H}$ ratio in the Caravaca section suggest three climate warming events during the D-S transition, one of them probably occurring at the D-S boundary.

Key words: Foraminifera, taxonomy, index-species, paleoecology, Paleocene, Spain.

Ignacio Arenillas [ias@unizar.es], Departamento de Ciencias de la Tierra (Paleontología) and Instituto Universitario de investigación de Ciencias Ambientales (IUCA) of Aragón, Universidad de Zaragoza, E-50009 Zaragoza, Spain. 
This is an open-access article distributed under the terms of the Creative Commons

Attribution License (for details please see creativecommons.org), which permits unrestricted use, distribution, and reproduction in any medium, provided the original author and source are credited.

FoFif Full text $(1,930.1 \mathrm{kB})$ ।

Far Supplementary file $(30.7 \mathrm{kB})$ 